\title{
PENGGUNAAN METODE ILEARNING UNTUK MENINGKATKAN KUALITAS PEMBELAJARAN DI PERGURUAN TINGGI
}

\author{
Henderi $^{1}$ \\ Muhamad Yusup ${ }^{2}$ \\ Yulika Ayu Rantama ${ }^{3}$ \\ e-mail : henderi@faculty.raharja.ac.id; muhamadyusup@faculty.raharja.ac.id \\ Yulika.ayu@si.raharja.ac.id
}

Diterima : 1 Mei 2012 / Disetujui: 19 Juni 2012

\begin{abstract}
One of the problems faced by universities noday is still a lack of learning systems that can support good teaching and learning quality and efficient. Currently, there are still learning methods which are conventional in which learning is still running in one direction, where the student fixated on material submitted by the lecturer in front and make the student tend to feel tired and passive. As an alternative to solving the problem is to provide the latest teaching innovations iLearning System (Integrated Learning), or in Indonesian called integrated learning system that is applied is one form to improve the quality to a modern and quality education. The reason the application of this method of learning iLearning we hope to provide a learning system that is more active and has a strong reciprocity between faculty and students, because the learning process of innovative and efficient will certainly add to the fun and spirit of the student so that the student was will not feel bored and passive. Using iLearning student can learn more optimally, they can see and read materials provided by lecturers in their respective iPad. Not only that students can easily do exercises / quiz, browsing, sending tasks, discussed and recorded with iPad without having to spend a stationery. Given these practical learning may help in improving the quality of learning activities based iLearning on Higher Education, and eventually gained a graduate or Human Resources (HR) that are reliable and able to compete in an era of globalization characterized by high competition.
\end{abstract}

Key words: iLearning, learning

1. Dosen Jurusan Sistem Komputer, STMIK Raharja

Jl. Jend Sudirman No. 40 Modern Cikokol-Tangerang Telp. 5529692

2. Dosen Jurusan Teknik Informatika, AMIK Raharja

Jl. Jend Sudirman No. 40 Modern Cikokol-Tangerang Telp. 5529692

3. Mahasiswa Jurusan Sistem Informasi, STMIK Raharja

Jl. Jend Sudirman No. 40 Modern Cikokol-Tangerang Telp. 5529692 


\begin{abstract}
ABSTRAKSI
Salah satu masalah yang sering dihadapi perguruan tinggi saat ini adalah masih kurangnya sistem pembelajaran yang dapat mendukung kualitas belajar mengajar yang baik dan efisien. Saat ini, metode pembelajaran yang ada masih bersifat konvensional dimana pembelajaran masih berjalan satu arah, dimana mahasiswa/i terpaku pada materi yang disampaikan oleh dosen didepan dan membuat mahasiswa/i cendrung merasa bosan dan pasif. Sebagai alternatif pemecahan masalah adalah memberikan inovasi pembelajaran terbaru yaitu Sistem iLearning, Sistem iLearning adalah sistem pembelajaran terpadu yang diterapkan merupakan salah satu bentuk untuk meningkatkan mutu menuju suatu pendidikan yang modern dan berkualitas. Alasan penerapan metode pembelajaran iLearning ini yaitu berharap dapat memberikan sistem pembelajaran yang lebih aktif dan memiliki timbal balik yang kuat antara dosen dan mahasiswa, karena proses belajar mengajar yang inovatif dan efisien tentunya akan menambah kesenangan dan semangat para mahasiswa/i sehingga mahasiswa/i pun tidak akan merasa jenuh dan pasif. Dengan itu mahasiswa pun dapat belajar lebih optimal, dan dapat melihat dan membaca bahan ajar yang diberikan oleh dosen pada iPadnya masing-masing. Tidak hanya itu mahasiswa/ $i$ pun bisa dengan mudah mengerjakan latihan-latihan/quiz, browsing, mengirim tugas, berdiskusi dan mencatat dengan iPad tanpa harus mengeluarkan alat tulis. Dengan adanya pembelajaran yang praktis ini semoga membantu dalam meningkatkan kualitas kegiatan pembelajaran berbasis iLearning pada Perguruan Tinggi, sehingga pada akhirnya diperoleh lulusan atau Sumber Daya Manusia (SDM) yang handal dan mampu bersaing di era globalisasi bercirikan high competition.
\end{abstract}

Kata kunci: iLearning, pembelajaran

\title{
PENDAHULUAN
}

Sambutan yang baik datang dari Departemen Pendidikan Nasional sebagai organisasi yang berfungsi mengelola pendidikan di Indonesia dengan memasukkan kurikulum yang mulai memperkenalkan teknologi informasi dan komunikasi. Respon yang baik ini menunjukkan bahwa Departemen Pendidikan Nasional sangat memperhatikan perkembangan dunia teknologi informasi dan komunikasi. Dan dalam dunia perguruan tinggi, e-learning sangat penting bukan hanya untuk mahasiswa semata, namun juga untuk para tenaga pengajar.

Bila belajar didefinisikan sebagai membaca, menulis, tentunya itulah metode pembelajaran yang kolot. Maka dibutuhkannya perubahan karena kini dunia sudah begitu maju dan akan selalu membutuhkan perkembangan dari berbagai sisi. Menciptakan suasana kelas yang membuat para mahasiswa lebih bersemangat dan merasa senang bukanlah hal yang mudah. Karena mahasiswa mudah sekali merasa jenuh. Itulah alasan mengapa perguruan tinggi perlu menciptakan iLearning sebagai terobosan baru. Dengan iLearning, memadukan antara belajar dan bermain, menyampaikan informasi dengan audiovisual yang lebih menarik, menjadikan suasana kelas yang lebih santai, itulah yang akan membuat perubahan.

Canggihnya sebuah alat teknologi tidak akan berfungsi bila alat tersebut hanya dijadikan alat mati dan bukan sebagai media dalam merubah metode pendidikan. Istilah e-learning yang muncul memang sudah membuat maju dunia pendidikan di Indonesia, begitu juga untuk perguruan tinggi. Namun, tetap harus terus menerus mengembangkannya mengikuti alur perkembangan teknologi yang ada. Dalam suatu Perguruan Tinggi, mutu pembelajaran merupakan salah satu peranan terpenting dalam setiap kegiatan yang dilakukan. Dan Perguruan Tinggi Raharja tentunya selalu ingin memberikan mutu yang baik untuk para mahasiswa/I dan dosen iLearning dipilih oleh perguruan tinggi Raharja sebagai metode baru dalam kegiatan Vol.6 No.3 - Mei 2013 
belajar mengajar. Dengan konsep yang sama namun lebih modern dan berkembang menjadikan iLearning sebagai andalan untuk perguruan tinggi yang mengharapkan dapat menciptakan lulusan yang lebih berkompeten. Konsep-konsep yang diambil mulai dari paperless hingga moderenisasi membuat perguruan tinggi yakin bahwa iLearning adalah kunci kesuksesan. Mengembangkan e-learning yang ada membuat iLearning merangkum konsep hingga terbentuk istilah 4B, yaitu Belajar, Bermain, Bekerja, Berdoa. Metode pembelajaran ilearning yang berjalan saat ini sudah cukup baik, namun masih diperlukannya perbaikan dari sisi metode dan infrastruktur. Agar proses belajar mengajar pun dapat berjalan dengan efisien dan efektif serta lebih terarah maka diperlukannya panduan pembelajaran ilearning. Sehingga proses belajar mengajar pun bisa berjalan dengan baik.

\section{PERMASALAHAN}

Perkembangan teknologi yang terus meningkat dengan cepat mendorong sistem pendidikan mengikuti laju perkembangan teknologi. Pendidikan dengan cara penyampaian yang baik dan menarik dengan memanfaatkan teknologi sebagai media penunjang komunikasinya mendukung kualitas pembelajaran yang bermutu. Tetapi saat ini sistem pendidikan dan pembelajaran yang digunakan masih bersifat monoton. Selain itu kurangnya media teknologi komunikasi yang menarik membuat terkadang mahasiswa cepat jenuh dan materi pembelajaran yang disampaikan menjadi tidak terserap optimal. Salah satu masalah yang dihadapi di Perguruan Tinggi saat ini adalah masih kurangnya sistem pembelajaran yang mendukung kualitas belajar mengajar yang baik dan efisien. Sebagai alternatif pemecahan masalah adalah memberikan inovasi pembelajaran terbaru yaitu Sistem iLearning, Sistem iLearning adalah sistem pembelajaran terpadu yang diterapkan merupakan salah satu bentuk untuk meningkatkan mutu menuju suatu pendidikan yang modern dan berkualitas. Sebuah perguruan tinggi akan tertarik dan mau menggunakan iLearning jika konsep yang digunakan menghasilkan tujuan yang sesuai standarisasi mutu pembelajaran yang di tetapkan. Perguruan Tinggi Raharja adalah sebuah lembaga pendidikan yang bergerak dibidang Pendidikan Teknologi Informasi. Karena itu Perguruan Tinggi Raharja harus dapat memenuhi tuntutan kualitas pembelajaran para mahasiswa di dalam perkuliahannya.

Sebelumnya telah diterapkan RME (Raharja Multimedia Edutainment) yaitu sebagai media online bagaimana dosen dan mahasiswa dapat mengakses materi perkuliahan mulai dari Pertemuan 1 sampai Pertemuan 14 dalam slide presentasi powerpoint atau file dokumen word. Setiap dosen dapat juga mengupload silabus, SAP, Tugas Mandiri Bank soal serta referensi. Sejak tahun 2011 metode perkuliahan iLearning mulai diterapkan di STMIK Raharja, sedangkan untuk perkuliahan non iLearning tetap berjalan dengan memanfaatkan RME dan buku paket sebagai media pembelajaran. Dan untuk kelas iLearning menggunakan iPad berupa iBooks sebagai media perkuliahan yang digunakan saat ini. Dengan memanfaatkan media pembelajaran iLearning diharapkan dapat meningkatkan mutu dan kualitas mahasiswa dalam belajar. Untuk sistem pembelajaran dengan metode iLearning ini tentunya didukung oleh beberapa aplikasi yang terdapat di iPad, seperti iBooks, Cram, InClass, Keynote, Number, dan Page. Aplikasi ini adalah beberapa contoh aplikasi yang mendukung berjalannya sebuah pembelajaran dengan sistem iLearning.

Metode pembelajaran dengan sistem iLearning ini memerlukan beberapa persiapan menuju pembelajaran berbasis iLearning. Metode dilaksanakan sebelum mahasiswa mengikuti pembelajaran iLearning, agar mahasiswa dapat mengerti bagaimana cara belajar dikelas yang tidak membosankan. Bayangkan jika semua mahasiswa hanya terpaku dikelas dengan materi perkuliahan yang hanya berisikan teori-teori, tentunya akan menimbulkan rasa jenuh dan 
bosan. Sesuai dengan konsep metode iLearning ini sendiri adalah belajar, bermain, bekerja, berdo'a.

\section{LITERATUREREVIEW}

Banyak penelitian yang sebelumnya dilakukan mengenai metode pembelajaran. Dalam upaya penembangan metode pembelajaran iLearning ini perlu dilakukan studi pustaka sebaai salah satu dari penerapan metode penelitian yang akan dilakukan. Diantaranya adalah mengidentifikasi kesenjangan (identify gaps), menghindari pembuatan ulang (reinventing the wheel), mengidentifikasikan metode yang pernah dilakukan, meneruskan penelitian sebelumnya, serta mengetahui oran lain yang spelialisasi dan area penelitianny sama dibidang ini. Beberapa Literatur review adalah sebagai berikut:

1. Penelitian ini dilakukan oleh By Chris Apers dan Daniel Paterson berjudul "Beginning iPhone and iPad Web Apps: Scripting with HTML5, CSS3, and JavaScri”. Penelitian ini membahas mengenai semua pengembangan Aplikasi iPhone, profesional web yang bekerja keras Dan sekarang dengan pengenalan iPad, kita mungkin merasa jauh tertinggal. Kita tidak perlu bekerja keras melalui Objective-C atau sentuh master Apple API Cocoa. WebKit dukungan untuk HTML5 berarti setiap web developer yang berkeinginan dapat bergabung gelombang kedua mobile App Apple dan membuat aplikasi menarik yang membahas fitur unik baik dari iPhone dan iPad lebih besar. Awal iPhone dan iPad Web Apps: Scripting dengan HTML5, CSS3, dan JavaScript membawa kita melalui setiap aspek terakhir Mobile Web Standard serta fitur khusus dari iPhone dan iPad. kita akan melampaui Web 2.0 dan Ajax untuk belajar tentang WebKit dan Mobile Safari, HTML5 dan CSS3, Vector Graphics dan dukungan multimedia. kita akan menemukan apa yang built-in fitur hardware iPhone dan iPad kita juga dapat digunakan bagaimana untuk mengambil keuntungan dari kemampuan perangkat khusus tersebut. Pasar untuk aplikasi Web adalah memperluas dan kombinasi dari iPhone dan iPad membuat ini sangat panas daerah-serta satu kompetitif. Apa yang anda pelajari bagaimana mengambil kemampuan yang ada web dan menyebarkannya di iPad dan iPhone dengan Dasar desain Pertemuan pengguna untuk kedua layar iPhone kecil dan layar besar iPad. Kunci untuk pengembangan aplikasi web yang dibangun ke HTML5, WebKit, dan Mobile Safari. Untuk mendukung mobile-media dengan iPhonedan fitur khusus iPad bagaimana untuk mengambil keuntungan dari fitur-fitur canggih untuk grafis CSS3. Alamat antarmuka layar sentuh Apple dan berinteraksi dengan sentuhan API Cocoa.[1]

2. Penelitian ini dilakukan oleh Dr. Rory Lewis berjudul "iPhone and iPad Apps for Absolute Beginners” tahun 2010. Penelitian ini membahas tentang bagaimana Anda membangun sebuah aplikasi untuk iPhone dan iPad? Apakah tidak Anda perlu menghabiskan tahun-tahun belajar bahasa pemrograman yang rumit? Bagaimana Objective-C, Kakao Touch, dan SDK? Jawabannya adalah bahwa Anda tidak perlu mengetahui hal-hal itu. Siapa saja bisa mulai membangun aplikasi sederhana untuk iPhone dan iPad, dan buku ini akan menunjukkan kepada Anda bagaimana caranya. [2]

3. Penelitian yang dilakukan oleh Glenn Fleishman, “ The best iPhone and iPad apps for work and play”. Ditetapkan untuk mengetahui cara menggunakan perangkat alam menemukan film, membaca buku, mengambil file dengan jarak jauh, membuat panggilan telepon, memainkan permainan atau strategi untuk mencapai host yang berguna, dan 
kadang-kadang melakukan tugas yang benar-benar tidak berguna. Glenn menyaring dan menguji ribuan aplikasi untuk menemukan hampir 200 program yang memenuhi kriteria-nya. Menarik, menghibur, berguna dan aplikasi yang memiliki lika bintang. Pilihannya yang jelas berguna akan mengejutkan anda dan membantu anda menyelesaikan tugas-tugas, bersenang-senang, menjadi kreatif, dan belajar sesuatu yang baru. apakah anda memerlukan aplikasi untuk melacak status pengiriman paket atau mengubah perangkat anda menjadi pembaca barcode? Mulai membaca dan pemindaian. Ingin menonton film terbaik dari studio atau ciptaan anda sendiri. Semua itu dapat diarahkan ke aplikasi yang sempurna. Aplikasi yang dapat memainkan musik sangat penting, membuat anda lebih produktif, dapat melacak file, dan masih banyak lagi.[3]

4. Penelitian yang dilakukan oleh Untung Rahardja, M.T.I, dkk “audio visual as one or the teaching as one or the teaching resources on iLearning”. Penelitian ini merupakan metode pembelajaran dengan iLearning dam memanfaatkan media audio visual sebagai konten pendukung dapat membuat pembelajaran lebih menarik dan tentunya lebih terserap optimal oleh mahasiswa. Metode pembelajaran iLearning memerlukan content pendukung dan media yang tepat sebagai materi perkuliahan. Media yang dipilih hendaknya menunjang tujuan pembelajaran yang dirumuskan. Jika materi yang akan dipelajari adalah bagian-bagian yang penting dari benda, maka media penyampaian dapat dengan gambar seperti bagan slide dapat digunakan. Apabila yang dipelajari adalah aspek-aspek yang menyangkut gerak, maka media penyampaian denagn video atau film akan lebih tepat.[4]

5. Penelitian yang dilakukan oleh Untung Rahardja, M.T.I, dkk. [Raharja 2011] "iBooks standardization and good practice for effective education methods insupport of iLearning”. Penelitian ini merupakan metode yang mengintegrasikan sumber daya dalam menjalankan Tridarma Perguruan Tinggi dengan menggunakan iPad. Maka dari itu dalam menjalankan metode iLearning dibutuhkan sebuah aplikasi yang mendukung berjalannya metode tersebut. iBooks adalah salah satu aplikasi yang mendukung iLearning.[5]

6. “iLearning: concept and applications" adalah judul dari penelitian yang dilakukan oleh Soekartawi (2002b). iLearning dapat dilihat dari perspektif yang berbeda. Hal ini mengacu pada istilah generic untuk semua didukung tekhnologi pembelajaran menggunakan sebuah array dari mengajar dan belajar alat-alat sebagai ponsel menjembatani, audio dan kaset video, telekonferensi, transmisi satelit, dan pelatihan berbasis web lebih diakui atau computer dibantu instruksi juga sering disebut sebaga online program. iLearning berkembang sangat cepat karena keuntungan yang cepat dari transformasi digital global di sektor pendidikan. Mengetahui keuntungan iLearning sebagai kompetensi meningkatkan belajar siswa, meningkatkan efisiensi kerja, .mengurangi masalah personil kekurangan, meningkatkan kualitas dan kesetaraan dalam pendidikan - itu adalah percaya bahwa hal itu dpata digunakan sebagai model alternative dalam mengatasi masalah pada kualitas dan kesetaraan dalam pendidikan dan kebutuhan bagi orang untuk melakukan :belajar untuk mengetahui, belajar melakukan, belajar untuk menjadi, belajar untuk hidup bersama, seperti yang disarankan oleh UNESCO dalam 'empat pilar’ belajar. Oleh karena itu disarankan melakukan studi kelayakan ketika salah satu ingin untuk berfikir tentang iLearning. iLearning secara teknis mungkin ekonomis menguntungkan dan secara social dapat diterima.[6] 
7. Penelitian yang dilakukan oleh Matthew Young Kim di Kennesaw State University Kennesaw, GA, USA. Pada tahun 2011 dengan judul "Simulation Study of eLearning Classroom using iPads Based on Wireless LAN with IEEE 802.11b” menyajikan studi simulasi kelas eLearning menggunakan iPad sebagai perangkat mobile berbasis pada LAN nirkabel dengan protokol IEEE 802.11b. Selain itu, makalah ini menyajikan sebuah studi simulasi apakah IEEE 802.11b dapat mendukung hingga 25 iPads dari kelas eLearning tanpa masalah keadilan pada Wireless LAN bersama. Simulasi dilakukan dengan OPNET IT Guru Academic Edition 9.1.[7]

Dari beberapa Literature Review diatas banyak peneliti yang melakukan penelitian seperti teknologi manajemen pengetahuan dan aplikasi, aplikasi iPhone dan iPad dan lain sebagainya. Namun belum adanya penelitian yang menerangkan secara gamblang tentang penggunaan metode iLearning untuk meningkatkan kualitas pembelajaran di Perguruan Tinggi.

\section{PEMECAHANMASALAH}

Untuk menerapkan sistem pembelajaran yang baru di sebuah perguruan tinggi, metode yang digunakan dalam penelitian meliputi variabel yang diteliti, objek oriented, objek design dan implementasi. Pada beberapa bagian penelitian yang menggunakan metode kualitatif, dapat dijelaskan pendekatan yang digunakan, proses pengumpulan dan analisis informasi, proses penafsiran dan penyimpulan hasil penelitian.

Rancangan penelitian. Penelitian dirancang dengan memanfaatkan semua sumber daya yang sudah tersedia di Raharja Enrichment Center, membentuk tim khusus yang disebut iRaharja, menjalankan training RiJP dan iCP, melakukan pertemuan khusus para ahli (sandbox meeting). Teknik Pengumpulan Data. Teknik pertama adalah LTK (Learn to Know), LTL (Learn to Learn), LTLT (Learn to Live Together), LTD (Learn to Do), dan LTB (Learn to Behave). Teknik Analisa Data. Teknik pertama adalah memahami masalah, mencari pembaharuan dari sistem pembelajaran yang sedang terjadi di seluruh dunia.

Cara penelitian dan penafsiran. Cara pertama adalah menganalisis kelemahan sistem pembelajaran lama dan kendala yang sering terjadi. Cara kedua adalah merancang sistem pembelajaran yang baru. Cara ketiga adalah persiapan untuk mencari keunggulan yang akan digunakan pada sistem pembelajaran yang baru yang akan digunakan. Cara keempat adalah membentuk tim peneliti. Proses penafsiran dan penyimpulan hasil penelitian dengan cara berpikir logis, berpikir kreatif seperti melihat proses pemecahan masalah, meletakkan dasar, curah gagasan, kumpulkan pengetahuan dari tempat lain, melihat situasi dari semua sisi, mengubah posisi sesering mungkin. 


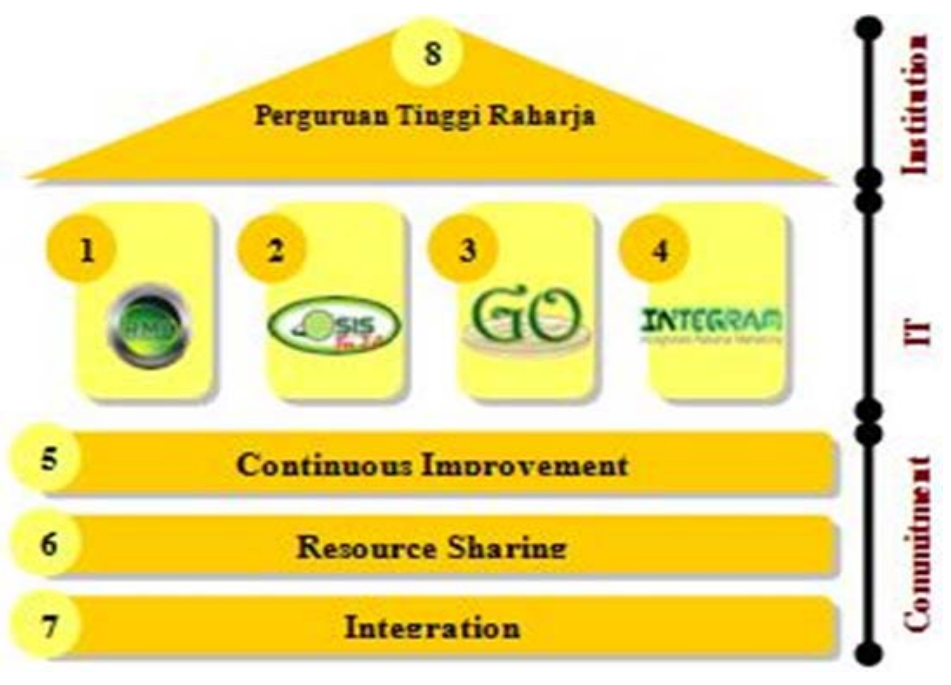

Gambar 1. (empat) Pilar IT E-Learning

Gambar diatas menjelaskan bahwa 4 (empat) Pilar IT E-learning tersebut berjalan harmonis membentuk bangunan yang kokoh pada institusi Perguruan Tinggi Raharja Informatika dengan ditopang oleh keberadaan IT E-Learning yang secara berkesinambungan melakukan perbaikan (countinue improvment), melakukan resource sharing dari dan oleh Pribadi Raharja serta saling terintegrasi (integration) satu sama lain. Dari 4 (empat) pilar IT Elearning tersebut, setiap sistem mempunyai batasan sistem (boundary) yang memisahkan sistem dengan lingkungan luarnya. Kesatuan luar merupakan kesatuan diluar sistem yang dapat berupa orang, organisasi, atau sistem lainnya yang memberikan input atau menerima output dari sistem. Definisi E-Learning itu sendiri adalah E-learning sebagai sembarang pengajaran dan pembelajaran yang menggunakan rangkaian elektronika (LAN, WAN, atau internet) untuk menyampaikan isi pembelajaran, interaksi atau bimbingan (Henderi 2011:319).[8] Hasil dan pembahasan pada penelitian ini merupakan 4 (empat) tujuan yang ingin dicapai adalah sebagai berikut:

1. Membangun Sistem Pembelajaran baru yang berbasis hi-Tech dengan penyempurnaan sistem yang sudah ada

2. Merubah metode belajar mengajar dengan sistem yang lama menjadi metode yang lebih efektif, efisien, paperless dan atraktif.

3. Merubah cara pandang para tenaga pengajar dan mahasiswa tentang belajar yang sebelumnya merupakan hal yang membosankan namun kini dengan iLearning suasana kelas akan jauh lebih nyaman dan menyenangkan.

4. Penerapan sistem 4B (Belajar, Bermain, Bekerja, Berdoa) yang dikerjakan secara bersamaan hanya dengan satu buah alat kecil yang disebut iPad.

Sistem iLearning adalah mengintregasikan sumber daya dalam menjalankan Tri Dharma Perguruan Tinggi dengan menggunakan iPad.[9] iLearning adalah setiap waktu senangsenang, setiap waktu belajar, lebih banyak fun lebih banyak belajar (M.Yusup, 2011).[10] Best practice teknologi pembelajaran yang dikembangkan dengan mengintegrasikan perangkat 
hardware, software, aplikasi, ICT, dan iPad yang dimiliki oleh peserta pembelajar dalam satu kesatuan (unity) yang bersifat unik untuk setiap peserta pembelajar, dan menjadi enabler untuk melaksanakan pembelajaran tingkat tinggi (high level learning) karena berpotensi tinggi dan mampu menstimulasi pengembangan berbagai jenis kecerdasan yang dimiliki manusia .Berikut adalah Maind Map dari metode pembelajaran iLearning ini:

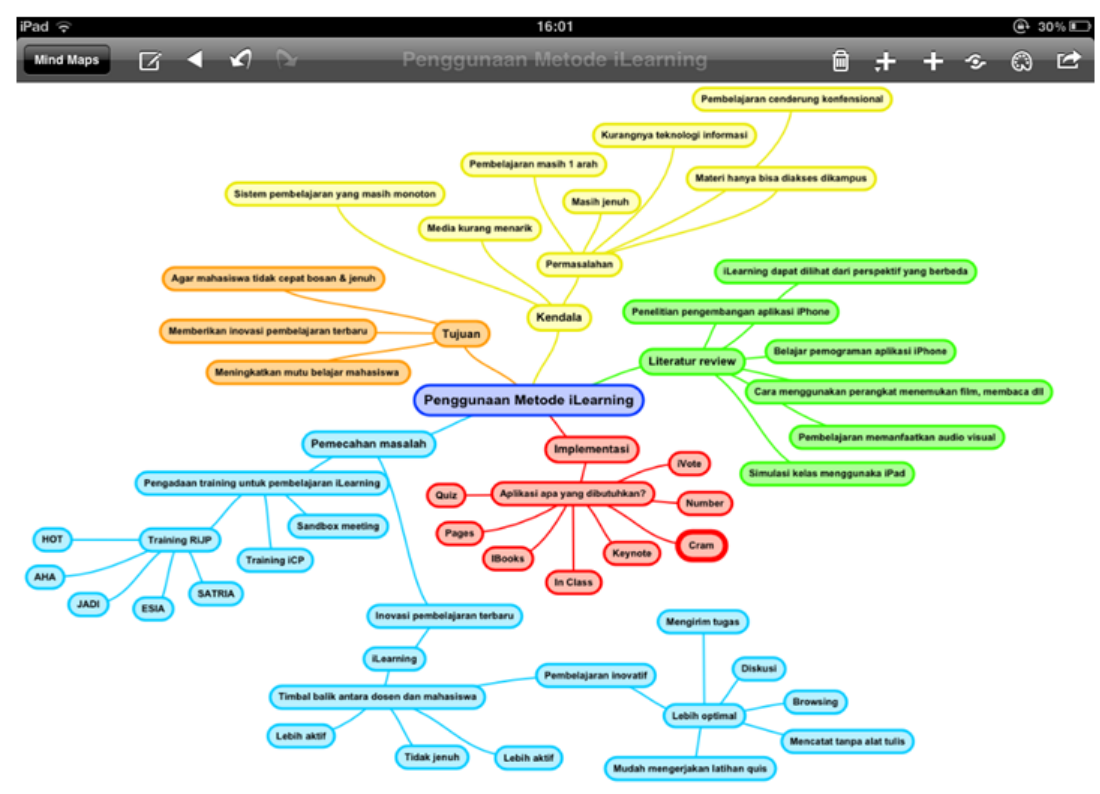

Gambar 2. Maind Map metode pembelajaran iLearning

Untuk membuat sistem yang baru bukanlah hal yang mudah, banyak persiapan yang harus dilakukan sebelum sistem itu benar-benar digunakan. Persiapan yang dilakukan oleh perguruan tinggi Raharja sebelum menuju sistem yang baru sangat banyak. Untuk memberikan fasilitas iPad kepada para mahasiswa khusus iLearning Class, tentunya harus ada persiapan yang matang. Berikut adalah beberapa persiapan yang dilakukan Perguruan Tinggi Raharja sebelum memulai memasuki sistem pembelajaran baru yang disebut iLearning.

\section{Training RiJP (Raharja iLearning Junior Professional)}

Persiapan yang dilakukan bukan hanya pada sistemnya saja, namun Perguruan Tinggi Raharja juga harus melakukan persiapan terhadap para mahasiswa yang nantinya akan menggunakan sistem pembelajaran iLearning. Para mahasiswa harus diperkenalkan terlebih dahulu tentang iPad, karena sebagian besar mahasiswa belum mengetahui atau belum terbiasa menggunakan iPad. Training ini dibuka untuk semua mahasiswa iLearning Class, mahasiswa diberikan pelatihan mulai dari perkenalan iPad hingga pengoprasian dasar iPad dan pengenalan tentang apa itu iLearning. Dengan adanya training iLearning ini, diharapkan nantinya mahasiswa tidak canggung mengikuti belajar mengajar dimulai. Mahasiswa lagi akan bertanya bagaimana cara untuk mengoperasikan iPad. Saat dimulainya kegiatan belajar mengajar berarti para 
pengajar dan mahasiswa harus siap untuk memulai perkuliahan. Berikut adalah lima Training iLearning yang wajib diikuti oleh mahasiswa iLearning Class Perguruan Tinggi Raharja.

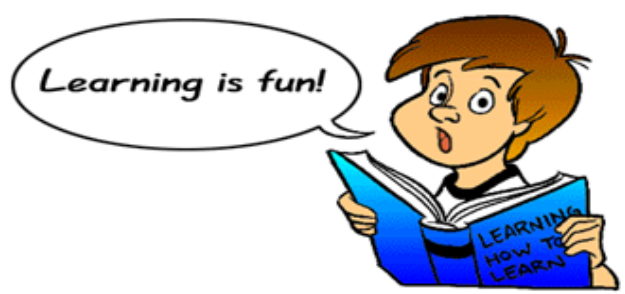

Step 6y Step Training iLearning
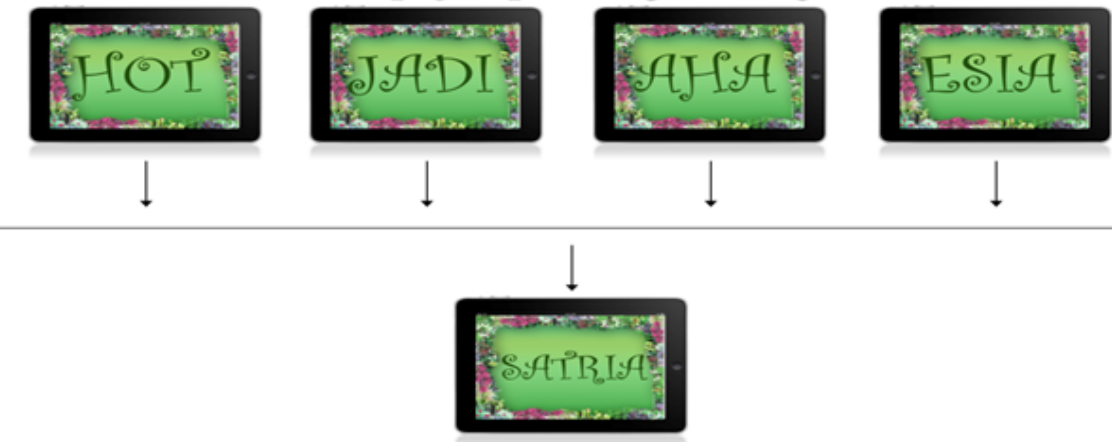

Enjoy and Have Fun Your Study in Here

Gambar 3. Training RiJP

a) $\operatorname{HOT}($ How To)

Training yang diberi nama HOT ini berisikan materi tentang pengenalan dasar iPad. Para peserta training akan diberikan informasi tentang tools-tools yang ada di iPad dan juga beberapa fungsinya.

b) JADi (Jelajah Appstore Di iPad)

Training yang diberi nama JADi ini berisikan materi tentang ekplorasi Appstore Apple dan juga cara bagaimana membuat ID Apple, install aplikasi, remove aplikasi dan halhal lain yang berkaitan dengan aplikasi.

c) AHA (AkHirnya Aku tahu)

Training yang diberi nama AHA ini berisikan materi tentang tips \& trik iPad, para peserta diberikan tugas untuk mencari tahu tentang beberapa tips \& trik iPad juga beberapa fungsi-fungsi iPad terbaru yang sebelumnya tidak dibahas dalam pelatihan. Hal ini berfungsi agar para mahsiswa/i lebih mengenal device yang nantinya akan menjadi alat utama dalam menjalankan kegiatan belajar mengajar.

d) ESIA (Education Simulasion In clAss)

Training yang diberi nama ESIA ini berisikan materi tentang iBooks, karena iBooks adalah aplikasi penting yang akan banyak dipakai oleh para pelajar untuk iLearning Class, maka harus sudah diperkenalkan tentang aplikasi iBooks ini. Aplikasi yang 
akan menggantikan fungsi buku yang mendukung metode paperless dan merupakan salah satu kunci akan berjalannya iLearning nanti.

e) SATRIA (Sekarang Saya Tahu Raharja Itu Amazing)

Training yang diberi nama SATRIA ini adalah training terakhir yang harus dilaksanakan oleh para mahasiswa iLearning Class. Pada training ini para mahsiswa diberikan project akhir yang harus diselesaikan sebelum dinyatakan lulus. Setelah project ini selesai, para mahsiswa berhak mendapatkan sertifikat yang berisi nilai-nilai training sebelumnya. Selain itu mahasiswapun juga akan menerima iPad license card yang menandakan berhak untuk mengoperasikan iPad setelah berhasil mengikuti semua tahapan training dan dinyatakan lulus. Sertifikat dan iPad license card yang dijadikan panduan untuk para mahasiswa iLearning Class apakah para mahasiswa tersebut berhak menerima iPad atau tidak dari perguruan tinggi Raharja.

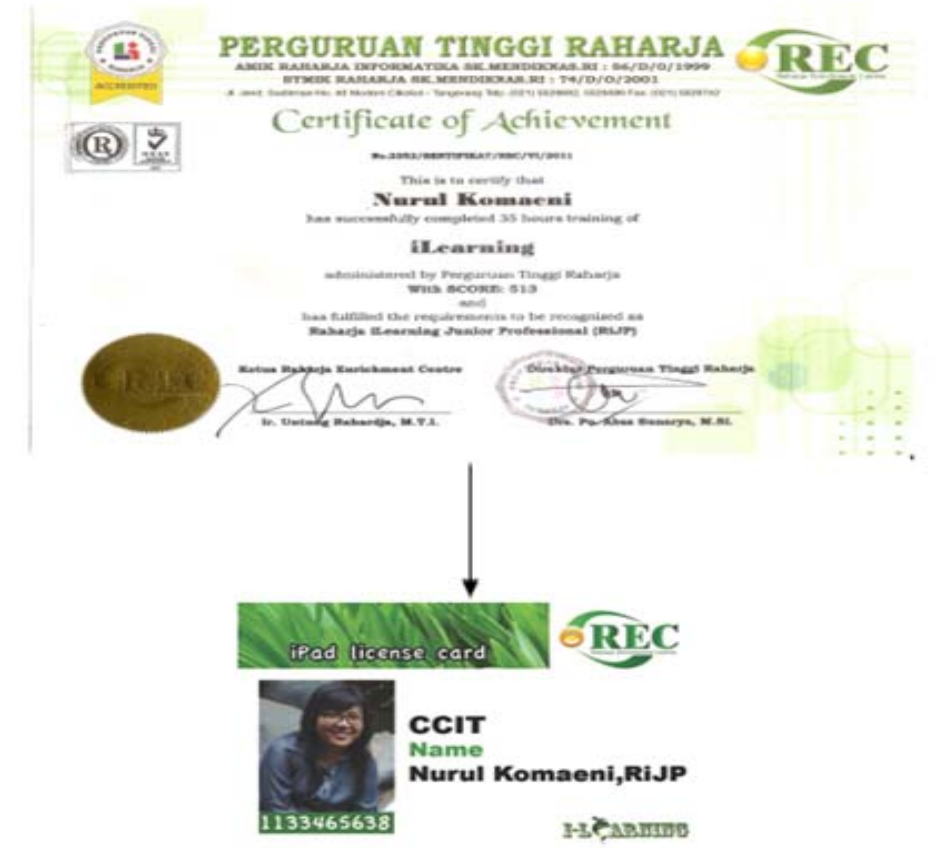

Gambar 4. Sertifikat dan iPad license card

2. Training iCP (iLearning Certificate Professional)

Jika persiapan kepada mahasiswa yang nantinya akan menggunakan sistem iLearning ini sudah dilakukan, selanjutnya diperlukan juga persiapan terhadap para tenaga pengajar yang nantinya menjadi inti dikelas pada saat perkuliahan berlangsung. Sistem ini tentunya bukan berlaku hanya pada para pelajar saja, namun juga pada para pengajar. Sistem pembelajaran yang baru menuntut para pengajar untuk membuat metode mengajar yang baru juga. Pada training iCP ini, para tenaga pengajar diberikan pelatihan yang hamper sama dengan pelatihan yang diberikan kepada para pelajar. Namun training iCP ini lebih 
berfokus pada pembentukan metode baru dalam cara mengajar. Para tenaga pengajar diberikan pengarahan khusus tentang tujuan utama dari iLearning, memberikan pemahaman tentang apa yang ingin dicapai oleh sistem pembelajaran iLearning ini. Dengan memanfaatkan ratusan aplikasi yang terinstal di iPad, para tenaga pengajar berusaha semaksimal mungkin agar iLearning berjalan dengan baik pada saat perkuliahan berlangsung, dan tujuan utama iLearning pun tercapai. Perbedaan antara training RiJP dan iCP adalah project akhir yang telah diselesaikan selesaikan. Pada training iCP, para pengajar diwajibkan untuk membuat sebuah presentasi sebagai project akhir. Presentasinya berisi tentang simulasi tentang gambaran pada saat berlangsungnya perkuliahan. Setiap pengajar (dosen khusus iLearning Class) harus mengekplorasi sedikitnya satu buah aplikasi penting yang menjadi default application untuk dikelas.

\section{Sandbox Meeting}

Sandbox meeting adalah sebuah pertemuan yang diadakan oleh beberapa orang untuk membentuk komunikasi lebih intens yang mendiskusikan masalah tehnikal iLearning. Didalam pertemuan ini para sandbox member berdiskusi tentang apa saja persiapan yang harus dilakukan, apasaja aplikasi yang akan digunakan. Didalam sandbox ini diharapkan agar member bisa mengungkapkan apa saja ide-ide penting yang dimiliki yang bisa langsung tertuang dalam sebuah sikusi yang diharapkan dapat memecahkan permasalahan yang berlum sempat terjawab. Banyaknya persiapan yang harus dilakukan membuat sandbox ini sangat penting untuk persiapan menuju perubahan sistem pembelajaran di perguruan tinggi Raharja.

Tabel 1. Perbandingan antara e-Learning dan i-Learning dari berbagai aspek

\begin{tabular}{|c|c|c|c|}
\hline NO & ASPEK & E-LEARNING & I-LEARNING \\
\hline 1 & MOTIVASI & + & ++ \\
\hline 2 & EFISIENSI & + & ++ \\
\hline 3 & PAPERLESS & + & ++ \\
\hline 4 & ATTRACTIVE & + & ++ \\
\hline
\end{tabular}

Berdasarkan Tabel 1. data di atas dapat dianalisis bahwa dari segi aspek:

- Motivasi, dua kali lipat lebih baik dibandingkan dengan e-Learning.

-- Efisiensi, dua kali lipat lebih baik dibandingkan dengan e-Learning.

-- Paperless, dua kali lipat lebih baik dibandingkan dengan e-Learning.

- Attractive, dua kali lipat lebih baik dibandingkan dengan e-Learning.

Secara umum pengaruh iLearning terhadap mahasiswa dan tenaga pengajar di perguruan tinggi Raharja dalam mengimplementasikan pembelajaran berbasis iLearning dapat diperinci:

1. Secara umum pengetahuan guru tentang pembelajaran iLearning sudah

baik karena sudah melewati lima tahapan training dan sudah dinyatakan lulus.

- 2. Kondisi mahasiswa perguruan tinggi khusus iLearning Class sebenarnya dalam pengetahuan umum iLearning sudah baik, karena telah melewati lima tahapan training yang memberikan banyak pengetahuan seputar iPad dan iLearning.

- $\quad$ 3. Pengaruh iLearning terhadap pembelajaran dapat dilihat dari beberapa aspek. Dari kuisioner didapatkan data iLearning memberikan motivasi lebih untuk mahasiswa dan tenaga pengajar khusus iLearning Class 
iLearning merupakan gagasan yang dicetuskan pada tahun 2011 oleh Untung Rahardja sebagai Ketua REC (Raharja Enrichment Center) Perguruan Tinggi Raharja, bahwasannya akan dibuatnya sebuah revolusi untuk sistem pembelajaran yang ada. Kemajuan teknologi yang begitu pesat membuat dirinya ingin Perguruan Tinggi Raharja terus sejajar dengan kemajuan teknologi yang ada. Tentu saja ini semua bukan semata-mata dengan memenuhi fasilitas yang $\mathrm{Hi}$-Tech, namun beliau ingin adanya perubahan yang berarti didalam metode belajar mengajar. Kekurangan yang ada dalam sistem pembelajaran e-Learning, melatar belakangi munculnya iLearning ini. Fasilitas yang canggih ternyata tidak begitu mempengaruhi beberapa aspek penting untuk dunia pendidikan. Contohnya saja efektifitas. Alat-alat pendukung yang sudah canggih terdapat didalam kelas tetap saja tidak mengurangi angka ketidakhadiran mahasiswa. Tentu ini menjadi sebuah pertanyaan besar tentang apa penyebab yang sebenarnya terjadi. Banyak langkah dilakukan untuk menginvestigasi permasalahan itu, hingga akhirnya ada beberapa alasan yang sangat mempengaruhi kemunculan iLearning ini. Banyak mahasiswa merasa bosan dan jenuh dengan suasana kelas dan perkuliahan yang monoton. Tentu saja ini semua bukan karena fasilitas ataupun alat pendukung yang ada, ini semua karena sistem pembelajarannya. Dari sinilah iLearning menjadi satu-satunya solusi untuk memecahkan permasalahan itu. Tampilan Flowchart metode pembelajaran iLearning:

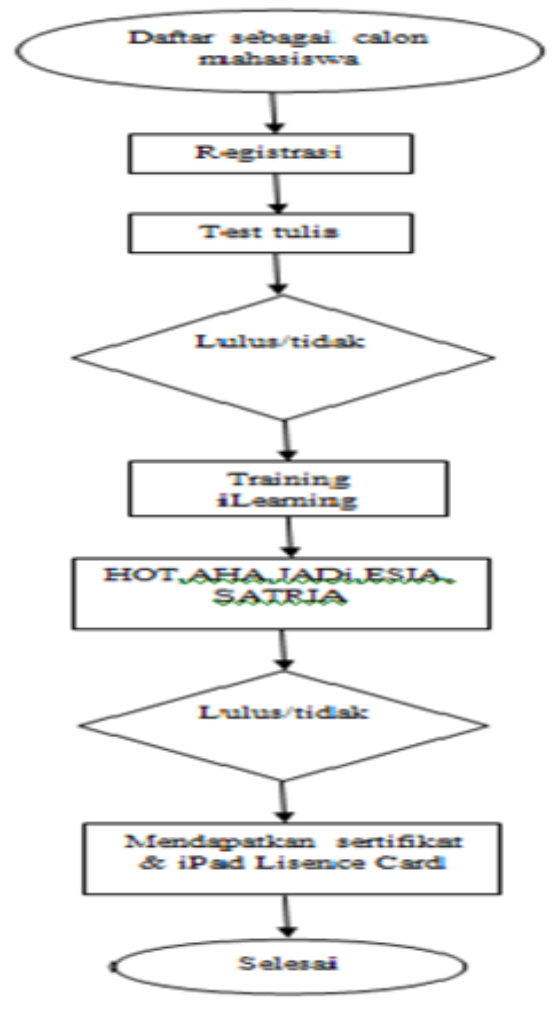

Gambar 11. Flowchart iLearning 


\section{IMPLEMENTASI}

Agar iLearning berjalan dengan sempurna, maka dibutuhkan beberapa aplikasi sebagai software pendukung. Antara lain :

1. InClass

Tasks, bye bye procrastination
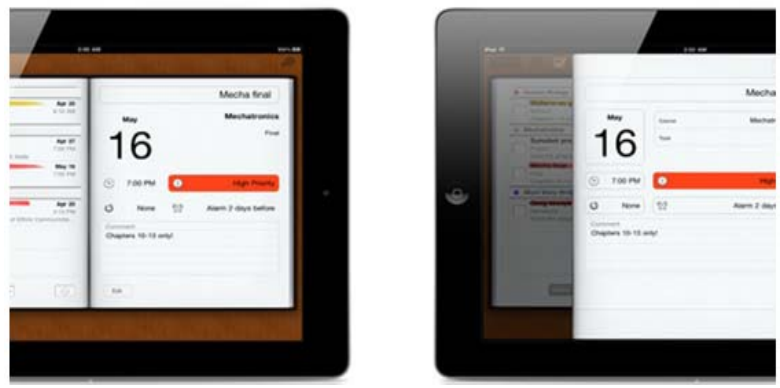

Gambar 5. InClass Application

Tampak pada Gambar 5. Aplikasi ini adalah aplikasi pendukung berjalannya iLearning di Perguruan Tinggi, dengan aplikasi ini para mahasiswa dapat mengatur jadwal kuliahnya dengan mudah dan dapat mencatat materi penting ataupun mengerjakan tugas yang nantinya akan dikirim melalui e-mail kepada dosen yang bersangkutan ataupun share melalui facebook.

\section{2. iBooks}

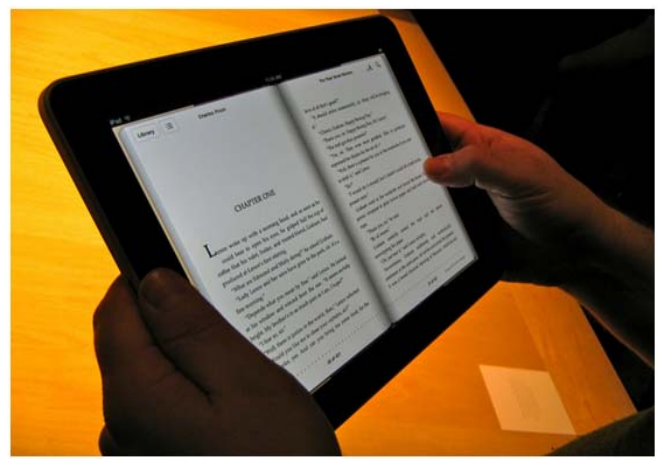

Gambar 6. iBooks Application

Tampak pada Gambar 6. Dengan aplikasi iBooks ini maka program paperless yang ada pada sistem pembelajaran iLearning dapat berjalan. Semua materi bahan ajar sudah tersimpan didalam iBooks yang mudah untuk diakses oleh semua mahasiswa di Perguruan Tinggi. Jika sebelumnya bahan ajar tersedia dalam bentuk slides presentasi, maka kini semua bahan ajar sudah tersedia didalam rak buku iBooks yang sudah tersimpan didalam iPad para mahasiswa. 
Kemudahan dalam mengoperasikannya, efisiensi dan beberapa hal yang dipertimbangkan untuk menggunakan iBooks sebagai aplikasi pengganti kertas dan program paperless pun berjalan dengan sempurna. Program paperless memiliki daya tarik tersendiri bagi para pelajar yang tidak suka dengan sesuatu yang kurang efisien. Beban tas yang biasanya dibawa oleh pelajar setidaknya 3-5 kg setiap hari, karena harus membawa materi bahan ajar dalam bentuk buku, membawa laptop dan lain-lain. Program paperless ini setidaknya memberikan solusi untuk itu semua.

\section{Cram}
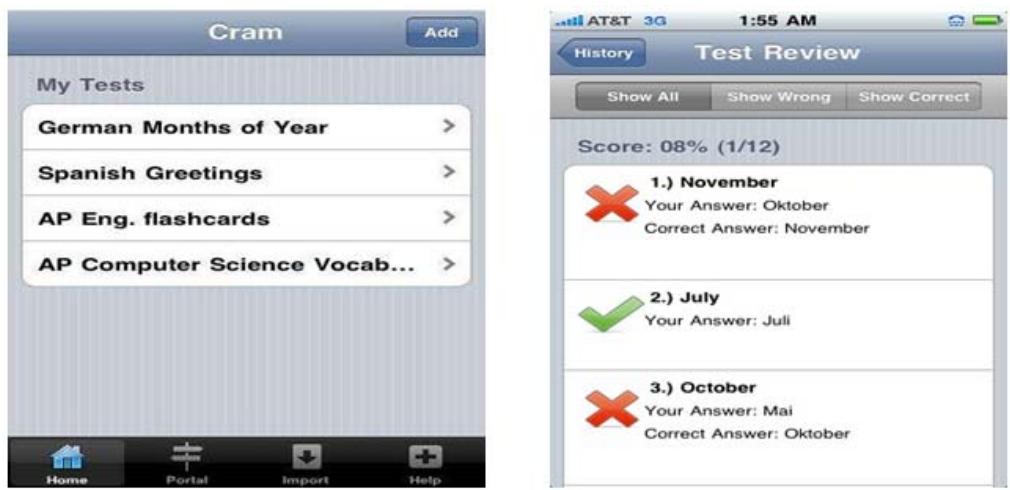

Gambar 7. Cram Application

Tampak pada Gambar 7. Aplikasi cram ini adalah aplikasi yang mendukung berjalannya quiz atau exam secara online, mahasiswa bisa langsung mengetahui nilai yang didapatkan setelah selesai mengerjakannya, tentunya hal ini sangat menarik, mahasiswa tidak perlu menunggu lama untuk mengetahui berapa nilai yang didapatkan. Hal ini dapat menghemat waktu dan juga penyajiannya yang begitu modern membuat sistem pembelajaran iLearning memang benar ingin membuat sebuah perubahan yang unik dari berbagai aspek yang ada.

\section{Pages}

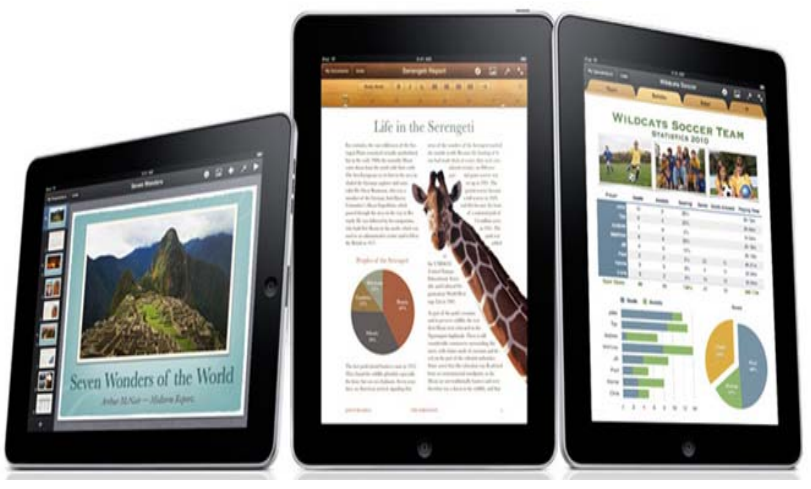

Vol.6 No.3 - Mei 2013

Gambar 8. Pages for iPad 
Tampak pada Gambar 8. Aplikasi pages ini digunakan untuk mengolah huruf dengan mudah. Berfungsi sama seperti Microsoft word. Hanya dengan sekali tap bisa membuat sebuah dokumen yang unik dan menarik, itulah alasan iLearning menggunakan aplikasi ini sebagai aplikasi pendukung.

\section{Numbers}

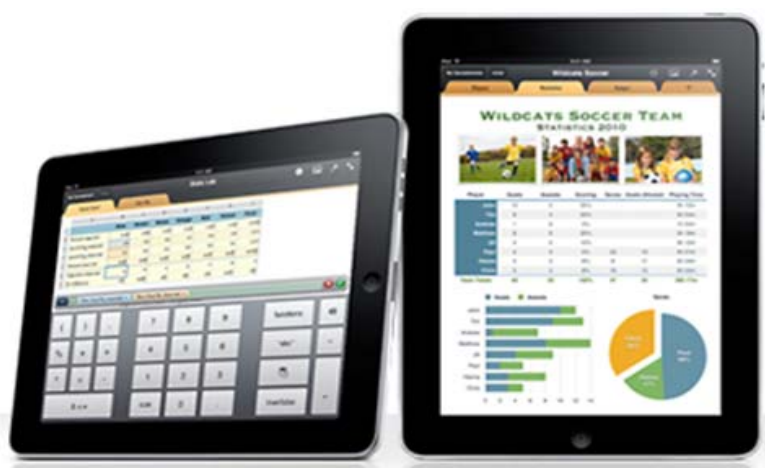

Gambar 9. Numbers for iPad

Tampak pada Gambar 9. Aplikasi Numbers ini berfungsi sama dengan Microsoft excel, sebagai pengolah angka. Dengan numbers siapapun bisa mengolah angka dengan praktis dan mudah. Numbers dipilih sebagai software pendukung iLearning karena berfungsi sebagai software pendukung di salah satu mata kuliah iLearning Class.

\section{Keynote}

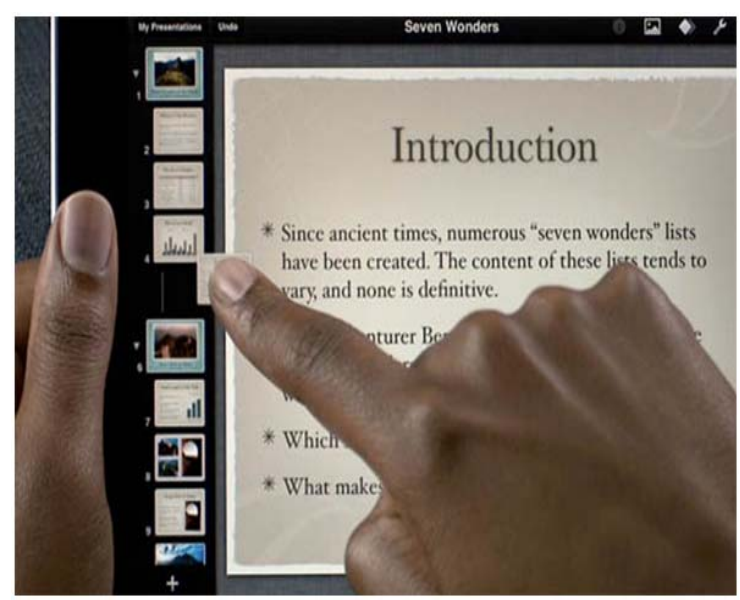

Gambar 10. Keynote for iPad 
Tampak pada Gambar 10. Aplikasi keynote ini digunakan untuk membuat presentasi dengan mudah hanya dengan sentuhan jari saja. Aplikasi pendukung iLearning ini dipilih untuk mempermudah para tenaga pengajar dan mahasiswa dalam mebuat presentasi. Berfungsi sama seperti Microsoft Powerpoint.

\section{KESIMPULAN}

iLearning yang dikembangkan pada penelitian ini telah diuji coba dan diimplementasikan di Perguruan Tinggi Raharja untuk mendapatkan best practice bagi pembelajaran di Perguruan Tinggi. Berdasarkan hasil evaluasi yang telah dilakukan terhadap pelaksanaan ujicoba dan implementasi tersebut, disimpulkan bahwa aplikasi iLearning pada penelitian ini merupakan penggunaan metode iLearning untuk meningkatkan kualitas pembelajaran di Perguruan Tinggi, Penerapan iLearning dapat meningkatkan kualitas pembelajaran karena iLearning menjadi enabler (pemungkin) mengoptimalkan berbagai jenis kecerdasan yang dimiliki oleh peserta pembelajar, diantaranya kecerdasan spasil, logika, bahasa, kenitik, bahkan pada batas-batas tertentu dalam mengoptimalkan kecerdasan emosional. Selain dapat meningkatkan kualitas proses pembelajaran, aplikasi iLearning pada penelitian ini juga dapat dikembangkan dan diterapkan untuk meningkatkan kualitas proses pelaksanaan evaluasi proses pembelajaran. Sistem iLearning merupakan penyempurnaan sistem pembelajaran konvensional bahkan sistem pembelajaran e-learning yang telah banyak diterapkan oleh banyak institusi pembelajaran, karena iLearning menerapkan dan memadukan konsep dan cara kerja 4B (Belajar, Bermain, Bekerja, Berdoa) dalam satu kesatuan. Dengan demikian iLearning dapat memberikan perubahan yang sangat fenomenal dalam proses pembelajaran karena dapat menciptakan proses pembelajaran yang nyaman dan menyenangkan. Menggunakan beberapa aplikasi pendukung seperti InClass, Cram, Pages, Keynote, Numbers, dengan aplikasi-aplikasi tersebut diharapkan iLearning memang mampu memberikan pembaharuan di Perguruan Tinggi dalam kegiatan belajar mengajar.

\section{DAFTAR PUSTAKA}

[1] Chris Apers dan Daniel Paterson, 2010, “Beginning iPone and iPad We Apps: Scripting with HTML5, CSS3, and JavaScri”.

[2] Rory Lewis 2010 "iPhone and iPad Apps for Absolute Beginners”

[3] Fleishman, Glenn. The best iPhone and iPad apps for work and play.

[4] Rahardja Untung, Immaniar Dewi, dkk (2012). Audio visual as one of the teaching resource on ilearning. Juranl CCIT Vol.5 No.2.

[5] Rahardja Untung, dkk (2011). iBooks Standardisation And Good Practice For Effective Education Methods In Support Of iLearning . Jurnal CCIT Vol.5 No.1.

[6] Soekartawi. 2007. iLearning: Concept and applicatiions. Jakarta 
[7] Matthew Young Kim 2011 "Simulation Study of eLearning Classroom using iPads Based on Wireless LAN with IEEE 802.11b

[8] Henderi, S.Kom,”Desain Aplikasi E-learning Sebagai Media Pembelajaran Artifical Informatics” CCIT Journal vol 4 no 3

[9] Rahardja Untung, (2011) “Definisi iLearning”. Raharja Enrichment Centre (REC). Tangerang.

[10] Yusup Muhamad, (2011) “Definisi iLearning”. Raharja Enrichment Centre (REC). Tangerang. 